\title{
Relationship between screen time and nutrient intake in Japanese children and adolescents: a cross-sectional observational study
}

Hiromasa Tsujiguchi ${ }^{1 *}$ D, Daisuke Hori ${ }^{1}$, Yasuhiro Kambayashi ${ }^{1}$, Toshio Hamagishi ${ }^{1}$, Hiroki Asakura' ${ }^{1}$ Junko Mitoma ${ }^{1}$,



Tadashi Konoshita ${ }^{2}$, Takiko Sagara', Aki Shibata', Satoshi Sasaki ${ }^{3}$ and Hiroyuki Nakamura'

\begin{abstract}
Background: Sedentary behaviors have recently become an important public health issue. We aimed to investigate the relationship between screen time and nutrient intake in children and adolescents.

Methods: The present study was conducted in 2013. Data were collected from children and adolescents aged between 6 and 15 years old in Shika town. Questionnaires were distributed to 1459 subjects, 1414 of whom participated in the study (96.9\%). Sedentary behaviors were assessed based on participants' screen behaviors (television (TV) viewing, personal computer (PC) use, and mobile phone (MP) use). The main outcomes were the intake of nutrients from a validated food frequency questionnaire. Analysis of covariance (ANCOVA) was used to examine the significance of differences in nutrient intake estimates. Multivariate linear regression analyses, adjusting for age, BMI, and physical activity, were used to provide parameter estimates $(\beta)$ and $95 \% \mathrm{Cl}$ for the relationship between screen time and nutrient intake.
\end{abstract}

Results: In boys, longer TV viewing times correlated or tended to correlate with a lower intake of protein, potassium, calcium, iron, vitamin $\mathrm{K}$, vitamin B-2, and total dietary fiber. In girls, longer TV viewing times correlated with a lower intake of protein, sodium, calcium, vitamin D, and vitamin B-2. Longer TV viewing times correlated with a higher intake of $\mathrm{n}-6$ fatty acids in girls. $\mathrm{PC}$ use was related or tended to be related to a lower intake of potassium, iron, vitamin $\mathrm{K}$, and folic acid in boys, but not in girls. A relationship was observed between MP use and a lower intake of vitamin K in boys, and MP use and a higher intake of vitamin D in girls.

Conclusions: The present results revealed that longer TV viewing times are associated with less protein, minerals, vitamins, and total dietary fiber intake in children and adolescents. It was also revealed that boys with PC use have less minerals and vitamins. These results support the need to design intervention programs that focus on decreasing TV viewing time in both sexes and PC use in boys while encouraging adherence to dietary guidelines among children and adolescents.

Keywords: Screen, Television, Nutrients, Children, Adolescents

\footnotetext{
* Correspondence: t-hiromasa@med.kanazawa-u.ac.jp

${ }^{1}$ Department of Environmental and Preventive Medicine, Graduate School of

Medical Sciences, Kanazawa University, 13-1 Takaramachi, Kanazawa,

Ishikawa, Japan

Full list of author information is available at the end of the article
}

(c) The Author(s). 2018 Open Access This article is distributed under the terms of the Creative Commons Attribution 4.0 International License (http://creativecommons.org/licenses/by/4.0/), which permits unrestricted use, distribution, and reproduction in any medium, provided you give appropriate credit to the original author(s) and the source, provide a link to the Creative Commons license, and indicate if changes were made. The Creative Commons Public Domain Dedication waiver (http://creativecommons.org/publicdomain/zero/1.0/) applies to the data made available in this article, unless otherwise stated. 


\section{Background}

Sedentary behaviors have recently become an important public health issue. Sedentary behaviors are "sitting or lying tasks performed in the waking hours with low levels of energy expenditure" [1]. There is evidence to suggest that sedentary behaviors are linked to adverse health outcomes. Observational studies reported that a prolonged sedentary time, in particular time spent watching television (TV), was linked to an increased risk of obesity, type 2 diabetes mellitus, cardiovascular disease, and premature death $[2,3]$. However, these relationships are not always consistent across age, gender, or health outcomes.

Although sedentary behaviors have been suggested to contribute to young individuals being overweight and obese, the evidence obtained to support this remains controversial. This may be due to the influence of a third variable or co-existing health behaviors. One variable that may co-vary with sedentary behaviors is diet $[4,5]$. The consumption of a healthier diet reduces the risk of obesity and numerous chronic diseases [6].

Previous studies demonstrated that TV viewing was linked to a less healthy diet such as a lower intake of fruit and vegetables; the higher consumption of energy-dense snacks, drinks, and fast food; and a higher total energy intake in young individuals $[4,5]$. These findings suggest that dietary intake plays a role in the relationship between TV viewing and health [7]. However, the relationships among sedentary behaviors and nutrient intake have not been examined in sufficient detail in children and adolescents.

Most of the published research on sedentary and dietary behaviors has focused on TV viewing times [4, 5]. Due to the recent increase in non-TV screen times, more information is needed on the relationship between personal computer (PC) and mobile phone (MP) use and nutrient intake in children and adolescents.

Therefore, we herein aimed to investigate the relationship between screen time, including PC and MP use, and nutrient intake among children and adolescents. To the best of our knowledge, few studies have examined this relationship.

\section{Methods}

\section{Data and participants}

We utilized cross-sectional data from the Shika study in Shika town. Shika town is located in a rural area of Ishikawa prefecture, Japan, with a population of 21,061 individuals. Major industries include electronic component manufacturing, farming, construction, and tourism. The climate is humid subtropical. The Shika study is an ongoing population-based survey that aims to investigate the lifestyle and health status of the Japanese population. This cross-sectional study was primarily designed to assess nutrient intake and associated behaviors in a sample of Japanese children and adolescents. The present study was performed between October and December, 2013. Data were collected from the guardians of children aged between 6 and 15 years old in Shika town. Our laboratory signed a research agreement with Shika town for health promotion. All the students of compulsory school age who went to Elementary School or Junior High School in Shika town in 2013 were eligible to participate in the study. We distributed questionnaires in collaboration with these Schools. We visited each school and handed questionnaires to the school principal or the school nurse. The school principal or the school nurse handed them to the homeroom teacher. The homeroom teacher explained about questionnaires and handed them to students. Questionnaires were distributed to 1459 guardians through students, 1414 of whom participated in this study (96.9\%). We asked the guardians to fill in the questionnaire with their children, as much as they could, to reflect their children's usual behavior accurately, to the greatest extent possible.

\section{Primary measures \\ Screen time (independent variable)}

Sedentary behaviors were assessed based on the screen behavior of participants during the week. Screen behavior was assessed by asking about the time spent on each screen on an average school day. We categorized TV viewing times as moderate $(<2 \mathrm{~h} /$ day $)$ and higher $(\geqq 2 \mathrm{~h} /$ day $)$. This is consistent with the definitions of high and low TV viewing in the literature [8]. PC and MP use were categorized as non-users and users. When the participants viewed DVDs on $\mathrm{PC}$ or channel on YouTube, they counted such viewing times as PC using times, not as TV viewing times.

\section{Dietary variables (dependent variables)}

The main outcome was the intake of nutrients from the validated food frequency questionnaire. We utilized the brief self-administered dietary history questionnaire (BDHQ). BDHQ asks about dietary history during the preceding 1 month. BDHQ is based on a comprehensive version of a validated self-administered questionnaire (i.e., DHQ) [9]. BDHQ 3y, 10y, and 15y (for Japanese preschool children aged 3-6 years, elementary school children aged 7-12 years, and junior high school children aged 13-15 years, respectively) were developed by modifying the adult version. We used BDHQ 10y for the participants of elementary school and 15y for the participants of junior high school). Each BDHQ listed 54 to 67 food items, respectively, in view of the legibility and knowledge of food. The intake of energy and 99 nutrients was estimated using a computer algorithm for BDHQ. Nutrient intake was reported in terms of energy 
density (\% energy or per $1000 \mathrm{kcal}$ ). Its validity is currently moderate to low $[10,11]$. Therefore, we selected nutrients that were shown to have moderate validity in the study. Details on BDHQ are described elsewhere [9, 12-14]. Participants who reported less than $600 \mathrm{kcal}$ or more than $4000 \mathrm{kcal}$ energy intake per day were excluded from the analyses.

\section{Covariates (demographics, body weight status, and physical activity)}

Covariates included in the multivariable analysis consisted of age, body weight status, and physical activity (PA). Obese children are known to be more strongly affected by TV, with respect to their food intake, than children who are a normal weight or overweight [15]. Body weight status was based on body mass index (BMI) calculated from self-reported heights and weights. BMI was computed based on the standard formula $\left(\mathrm{kg} / \mathrm{m}^{2}\right)$ [6]. BMI was used to classify children as underweight, normal weight, and overweight (including obese) based on the International Obesity Task Force reference [16]. Although participation in sedentary behaviors and PA occur independently [17], research suggests that both types of PA-related behaviors may be associated with dietary behavior $[2,4]$. The questionnaire was used to assess the level of PA, which was evaluated by asking the time spent doing PA on an average school day.

\section{Statistical analysis}

All analyses were stratified by sex. Descriptive statistics were used to describe participants' demographics, health behavior, and nutrient intake. Categorical variables were presented as percentages (\%) and frequencies $(N)$. Continuous variables were summarized as the mean and standard deviation (SD). Analysis of covariance (ANCOVA), adjusting for age, body weight status, and PA, on screen time was used to examine significant differences in nutrient intake estimates. Multivariate linear regression analyses, adjusting for age, BMI, and PA, were used to provide parameter estimates $(\beta)$ and $95 \%$ confidence interval (CI) for the relationship between screen time and nutrient intake. Statistical Package for Social Science (SPSS) version 19 was used for these analyses. Statistical tests were two-sided at a significance level of $5 \%$.

\section{Results}

Gender differences in the prevalence of screen time, body weight status, PA, and nutrient intake

The characteristics of the studied population are shown in Table 1. Thirty-one boys and nine girls were excluded from the analyses. A total of 1374 participants provided data for the variables of interest and were included in the analyses. Boys accounted for $49.4 \%(N=679)$ of samples, while $50.6 \%(N=695)$ were girls. The average ages of the participants were $10.72(\mathrm{SD}=2.61)$ years for boys and $10.69(\mathrm{SD}=2.65)$ years for girls. The rate of participants who were overweight was significantly higher in boys $(p<0.001)$. The rates of participants using MP $(p<0.001)$ and being physically inactive $(p$ $<0.001)$ were significantly higher in girls. Boys were more likely to have a total energy intake $(p<0.001)$ and consume carbohydrates $(p<0.001)$. Girls were more likely to consume protein $(p=0.027)$, fat $(p<0.001)$, fatty acids (saturated fatty acids, $p=0.002 ; \mathrm{n}-3$ fatty acids, $p=0.010$; n-6 fatty acids, $p<0.001$ ), minerals (excluding calcium; sodium, $p<0.001$; potassium, $p<0.001$; iron, $p<$ 0.001 ), vitamins (excluding vitamin $\mathrm{D}$; vitamin $\mathrm{K}, p<$ 0.001 ; vitamin $\mathrm{B}-1, p=0.016$; vitamin $\mathrm{B}-2, p=0.003$; folic acid, $p<0.001$; vitamin $C, p<0.001)$, cholesterol $(p<0.001)$, and total dietary fiber $(p<0.001)$.

\section{Nutrients intake according to screen time}

There was a significant main effect of screen time on the consumption of nutrients. The following screen time correlated or tended to correlate with nutrient intake in ANCOVA (Tables 2, 3, and 4). The intake of protein $(p=0.005)$, minerals (excluding sodium; potassium, $p=0.064$; calcium, $p=0.005$; iron, $p=0.034)$, vitamin $\mathrm{K}(p=0.018)$, vitamin $\mathrm{B}-2(p=0.050)$, and total dietary fiber $(p 2=0.082)$ was lower in boys with longer TV viewing times. The intake of protein $(p 2=0.027)$, sodium $(p=0.071)$, calcium $(p<0.001)$, vitamin D $(p=0.079)$, and vitamin $\mathrm{B}-2$ $(p=0.032)$ was lower in girls with longer TV viewings. The intake of $\mathrm{n}-6$ fatty acids was higher $(p=0.028)$ in girls with longer TV viewings.

Boys who used PC had smaller intake of potassium $(p=0.056)$, iron $(p 2=0.060)$, vitamin $\mathrm{K}(p=0.029)$, and folic acid $(p=0.047)$. There was no difference in nutrient intake between girls who used PC and girls who did not use PC.

Boys who used MP consumed less vitamin K $(p=0.027)$. Girls who used MP were more likely to consume vitamin $\mathrm{D}(p=0.034)$.

\section{Relationship between screen time and nutrient intake}

The relationship between screen time and nutrient intake are shown in Tables 5, 6 and 7. The following nutrient intake remained correlated or tended to correlate with screen time.

In boys, longer TV viewing times correlated with a lower intake of protein $(\beta=-0.109, p=0.005)$, potassium $(\beta=-0.076, p=0.050)$, calcium $(\beta=-0.109, p=0.005)$, iron $(\beta=-0.084, p=0.029)$, vitamin $\mathrm{K}(\beta=-0.098, p=$ $0.011)$, vitamin $\mathrm{B}-2(\beta=-0.076, p=0.046)$, and total dietary fiber $(\beta=-0.074, p=0.051)$. In girls, longer TV viewing times correlated with a lower intake of protein $(\beta=-0.085, p=0.027)$, sodium $(\beta=-0.065, p=0.072)$, 
Table 1 The characteristics of the studied population

\begin{tabular}{|c|c|c|c|}
\hline & Boys & Girls & $p^{+}$ \\
\hline Number (N (\%)) & $679(49.4 \%)$ & $695(50.6 \%)$ & \\
\hline Age (average (SD)) & $10.72(2.61)$ & $10.69(2.65)$ & 0.843 \\
\hline \multicolumn{4}{|c|}{ Body mass index (BMI) categories (N (\%)) } \\
\hline Underweight & $39(5.7 \%)$ & $55(7.9 \%)$ & \multirow[t]{3}{*}{$<0.001$} \\
\hline Normal weight & $484(71.3 \%)$ & $545(78.4 \%)$ & \\
\hline Overweight & $156(23.0 \%)$ & $95(13.7 \%)$ & \\
\hline \multicolumn{4}{|l|}{ Physical activity (N (\%)) } \\
\hline$<1 \mathrm{~h}$ & $324(48.5 \%)$ & $424(62.2 \%)$ & \multirow[t]{3}{*}{$<0.001$} \\
\hline $1-3 h$ & $284(42.5 \%)$ & $221(32.4 \%)$ & \\
\hline$>3 \mathrm{~h}$ & $60(9.0 \%)$ & $37(5.4 \%)$ & \\
\hline \multicolumn{4}{|l|}{ Television (TV) viewing time $(N(\%))$} \\
\hline$<2 \mathrm{~h}$ & $390(58.6 \%)$ & $388(56.6 \%)$ & \multirow[t]{2}{*}{0.456} \\
\hline$>2 h$ & $275(41.4 \%)$ & $297(43.4 \%)$ & \\
\hline \multicolumn{4}{|l|}{ Personal computer (PC) using (N (\%)) } \\
\hline Non-user & $441(66.3 \%)$ & $454(66.4 \%)$ & \multirow[t]{2}{*}{0.982} \\
\hline User & $224(33.7 \%)$ & $230(33.6 \%)$ & \\
\hline \multicolumn{4}{|l|}{ Mobile phone (MP) using (N (\%)) } \\
\hline Non-user & $509(76.7 \%)$ & $465(68.1 \%)$ & \multirow[t]{2}{*}{$<0.001$} \\
\hline User & $155(23.3 \%)$ & $218(31.9 \%)$ & \\
\hline \multicolumn{4}{|l|}{ Nutrients intake (average (SD)) } \\
\hline Energy (kcal) & $1953.04(669.45)$ & $1676.75(568.94)$ & $<0.001$ \\
\hline Protein (\%E) & $13.95(2.31)$ & $14.22(2.28)$ & 0.027 \\
\hline Fat (\%E) & $27.82(5.30)$ & $29.10(5.13)$ & $<0.001$ \\
\hline Carbohydrate (\%E) & $56.61(6.57)$ & $55.30(6.32)$ & $<0.001$ \\
\hline Saturated fatty acids (\%E) & $9.17(2.20)$ & $9.55(2.22)$ & 0.002 \\
\hline n-3 fatty acids (\%E) & $1.03(0.29)$ & $1.07(0.29)$ & 0.010 \\
\hline n-6 fatty acids (\%E) & $4.88(1.15)$ & $5.14(1.08)$ & $<0.001$ \\
\hline Sodium (mg/1000 kcal) & $2279.26(537.76)$ & $2418.16(541.57)$ & $<0.001$ \\
\hline Potassium (mg/1000 kcal) & $1171.14(276.87)$ & $1237.82(267.08)$ & $<0.001$ \\
\hline Calcium (mg/1000 kcal) & $353.40(113.29)$ & $363.69(97.47)$ & 0.071 \\
\hline Iron (mg/1000 kcal) & $3.54(0.73)$ & $3.81(0.73)$ & $<0.001$ \\
\hline Vitamin D ( $\mu \mathrm{g} / 1000 \mathrm{kcal})$ & $5.01(2.90)$ & $5.08(2.87)$ & 0.674 \\
\hline Vitamin K ( $\mu \mathrm{g} / 1000 \mathrm{kcal})$ & $106.18(52.75)$ & $115.91(55.07)$ & 0.001 \\
\hline Vitamin B-1 (mg/1000 kcal) & $0.40(0.07)$ & $0.41(0.08)$ & 0.016 \\
\hline Vitamin B-2 (mg/1000 kcal) & $0.70(0.19)$ & $0.73(0.16)$ & 0.003 \\
\hline Folic acid ( $\mu \mathrm{g} / 1000 \mathrm{kcal})$ & $141.11(44.77)$ & $154.88(44.64)$ & $<0.001$ \\
\hline Vitamin C (mg/1000 kcal) & $49.85(22.18)$ & $55.24(22.78)$ & $<0.001$ \\
\hline Cholesterol (mg/1000 kcal) & $165.89(54.26)$ & $181.55(61.06)$ & $<0.001$ \\
\hline Total dietary fiber (g/1000 kcal) & $5.33(1.34)$ & $5.77(1.32)$ & $<0.001$ \\
\hline
\end{tabular}

${ }^{\dagger} t$ tests for continuous variables and $x^{2}$ tests for categorical variables

calcium $(\beta=-0.175, p<0.001)$, vitamin $\mathrm{D}(\beta=-0.064$, $p=0.096)$, and vitamin $\mathrm{B}-2 \quad(\beta=-0.079, p=0.035)$. Longer TV viewing times correlated with a higher intake of $\mathrm{n}-6$ fatty acids $(\beta=0.079, p=0.040)$.
PC use was related or tended to be related to the lower intake of potassium $(\beta=-0.076, p=0.059)$, iron $(\beta=-$ $0.075, p=0.061)$, vitamin $\mathrm{K}(\beta=-0.085, p=0.033)$, and folic acid $(\beta=-0.078, p=0.053)$ in boys, but not in girls. 


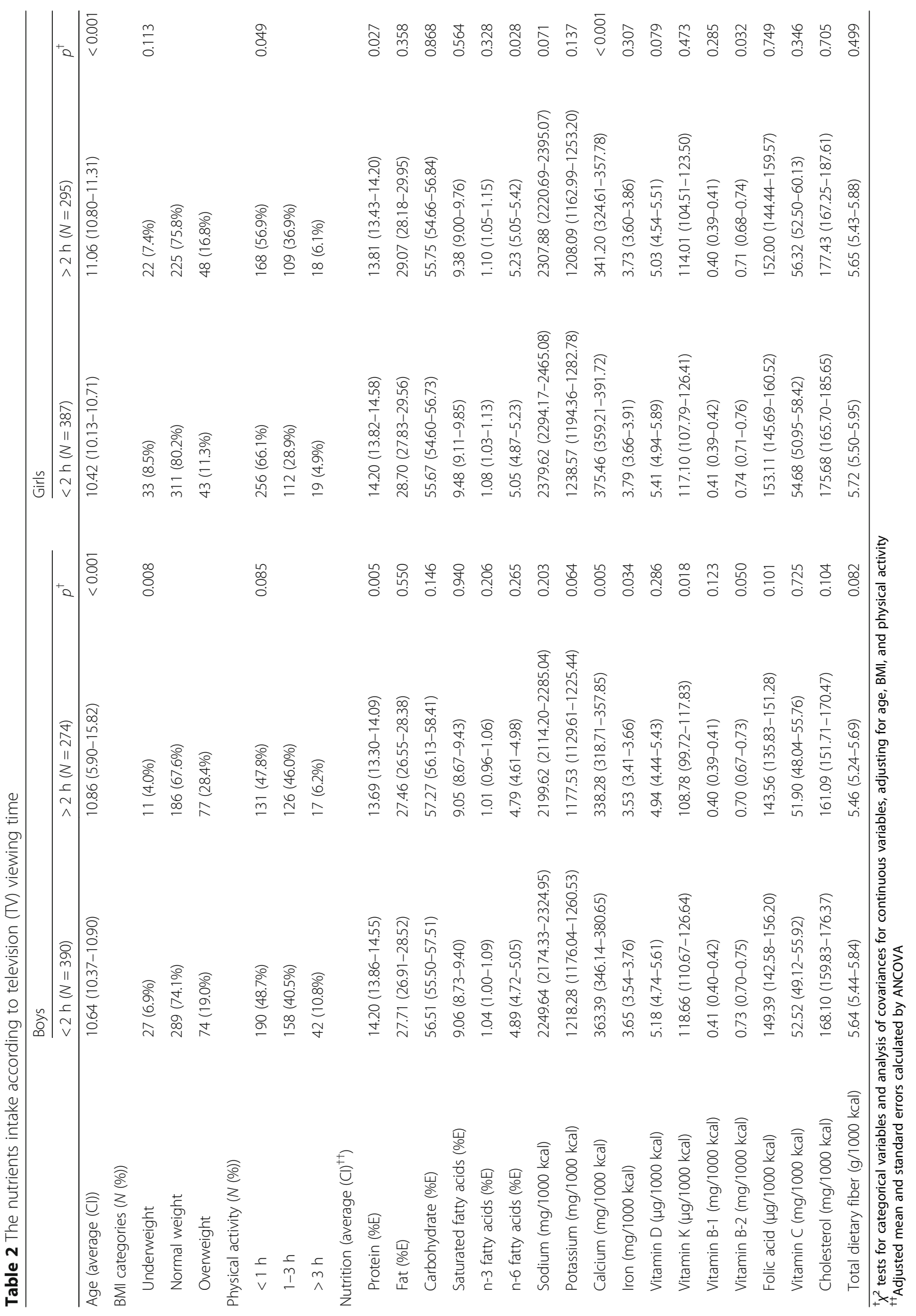









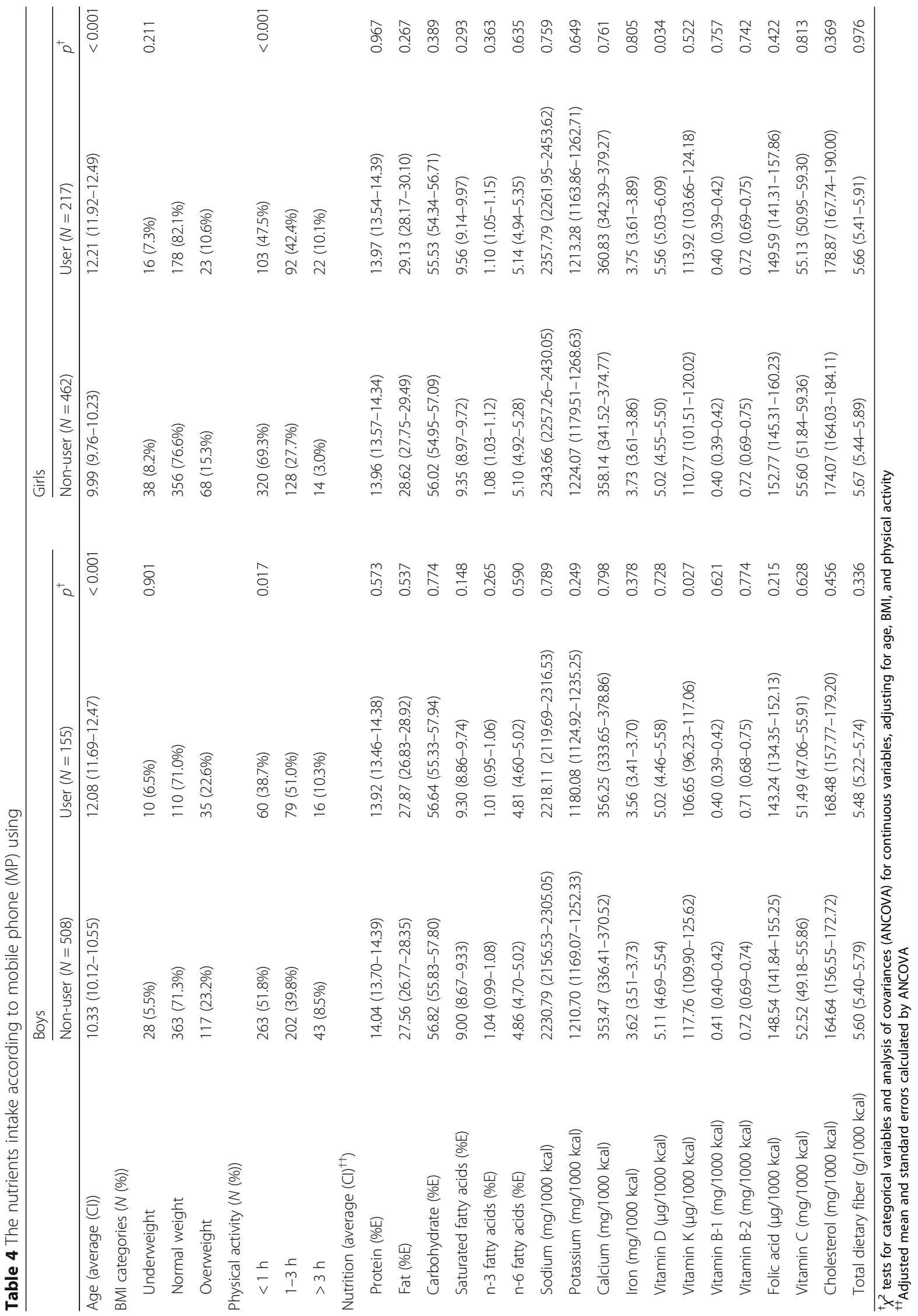


Table 5 The relationship between television viewing and nutrient intake

\begin{tabular}{|c|c|c|c|c|c|c|}
\hline & Boys $(N=$ & & & Girls $(N=$ & & \\
\hline & $\bar{\beta}$ & Lower $\mathrm{Cl}$ to upper $\mathrm{Cl}$ & $p^{\dagger}$ & $\bar{\beta}$ & Lower $\mathrm{Cl}$ to upper $\mathrm{Cl}$ & $p^{\dagger}$ \\
\hline Protein (\%E) & -0.109 & $(-0.184$ to -0.033$)$ & 0.005 & -0.085 & $(-0.159$ to -0.009$)$ & 0.027 \\
\hline Fat (\%E) & -0.019 & ( -0.096 to 0.058$)$ & 0.632 & 0.030 & $(-0.045$ to 0.107$)$ & 0.430 \\
\hline Carbohydrate (\%E) & 0.054 & $(-0.024$ to 0.131$)$ & 0.172 & 0.010 & $(-0.066$ to 0.085$)$ & 0.803 \\
\hline Saturated fatty acids (\%E) & 0.001 & $(-0.076$ to 0.077$)$ & 0.989 & -0.027 & $(-0.102$ to 0.048$)$ & 0.485 \\
\hline n-3 fatty acids (\%E) & -0.048 & $(-0.124$ to 0.029$)$ & 0.221 & 0.038 & $(-0.038$ to 0.113$)$ & 0.327 \\
\hline n-6 fatty acids (\%E) & -0.038 & $(-0.110$ to 0.034$)$ & 0.299 & 0.079 & (0.004 to .154) & 0.040 \\
\hline Sodium (mg/1000 kcal) & -0.046 & $(-0.110$ to 0.023$)$ & 0.200 & -0.065 & $(-0.126$ to 0.005$)$ & 0.072 \\
\hline Potassium (mg/1000 kcal) & -0.076 & $(-0.158$ to 0.000$)$ & 0.050 & -0.056 & $(-0.129$ to 0.018$)$ & 0.142 \\
\hline Calcium (mg/1000 kcal) & -0.109 & $(-0.189$ to -0.033$)$ & 0.005 & -0.175 & $(-0.246$ to -0.098$)$ & $<0.001$ \\
\hline Iron (mg/1000 kcal) & -0.084 & $(-0.159$ to -0.009$)$ & 0.029 & -0.038 & $(-0.112$ to 0.037$)$ & 0.328 \\
\hline Vitamin D ( $\mu \mathrm{g} / 1000 \mathrm{kcal})$ & -0.039 & $(-0.111$ to 0.035$)$ & 0.312 & -0.064 & $(-0.139$ to 0.011$)$ & 0.096 \\
\hline Vitamin K ( $\mu \mathrm{g} / 1000$ kcal) & -0.098 & $(-0.170$ to -0.022$)$ & 0.011 & -0.028 & $(-0.102$ to 0.047$)$ & 0.474 \\
\hline Vitamin B-1 (mg/1000 kcal) & -0.061 & $(-0.142$ to 0.015$)$ & 0.112 & -0.040 & $(-0.113$ to 0.034$)$ & 0.288 \\
\hline Vitamin B-2 (mg/1000 kcal) & -0.076 & $(-0.154$ to -0.001$)$ & 0.046 & -0.079 & $(-0.152$ to -0.006$)$ & 0.035 \\
\hline Folic acid ( $\mu \mathrm{g} / 1000 \mathrm{kcal})$ & -0.068 & $(-0.149$ to 0.009$)$ & 0.081 & -0.010 & $(-0.084$ to 0.064$)$ & 0.794 \\
\hline Vitamin C (mg/1000 kcal) & -0.016 & $(-0.097$ to 0.064$)$ & 0.683 & 0.038 & $(-0.036$ to 0.112$)$ & 0.313 \\
\hline Cholesterol (mg/1000 kcal) & -0.060 & $(-0.138$ to 0.016$)$ & 0.122 & 0.012 & $(-0.062$ to 0.085$)$ & 0.758 \\
\hline Total dietary fiber (g/1000 kcal) & -0.074 & $(-0.149$ to 0.000$)$ & 0.051 & -0.025 & $(-0.097$ to 0.049$)$ & 0.514 \\
\hline
\end{tabular}

${ }^{\dagger}$ Multivariate linear regression analyses, adjusting for age, BMl, and physical activity

Table 6 The relationship between personal computer using and nutrient intake

\begin{tabular}{|c|c|c|c|c|c|c|}
\hline & Boys $(N=$ & & & Girls $(N=$ & & \\
\hline & $\bar{\beta}$ & Lower $\mathrm{Cl}$ to upper $\mathrm{Cl}$ & $p^{\dagger}$ & $\bar{\beta}$ & Lower $\mathrm{Cl}$ to upper $\mathrm{Cl}$ & $p^{\dagger}$ \\
\hline Protein (\%E) & -0.051 & $(-0.131$ to 0.029$)$ & 0.208 & -0.014 & $(-0.095$ to 0.066$)$ & 0.725 \\
\hline Fat (\%E) & -0.013 & $(-0.093$ to 0.067$)$ & 0.749 & 0.037 & $(-0.044$ to 0.119$)$ & 0.367 \\
\hline Carbohydrate (\%E) & 0.028 & $(-0.053$ to 0.109$)$ & 0.495 & -0.026 & $(-0.108$ to 0.055$)$ & 0.523 \\
\hline Saturated fatty acids (\%E) & 0.001 & $(-0.079$ to 0.080$)$ & 0.984 & 0.052 & $(-0.029$ to 0.133$)$ & 0.206 \\
\hline n-3 fatty acids (\%E) & -0.050 & $(-0.130$ to 0.029$)$ & 0.216 & 0.023 & $(-0.058$ to 0.105$)$ & 0.571 \\
\hline n-6 fatty acids (\%E) & -0.044 & $(-0.119$ to 0.030$)$ & 0.243 & -0.016 & $(-0.097$ to 0.065$)$ & 0.692 \\
\hline Sodium (mg/1000 kcal) & -0.051 & $(-0.118$ to 0.021$)$ & 0.172 & -0.001 & $(-0.071$ to 0.070$)$ & 0.989 \\
\hline Potassium (mg/1000 kcal) & -0.076 & $(-0.162$ to 0.003$)$ & 0.059 & -0.025 & $(-0.104$ to 0.055$)$ & 0.538 \\
\hline Calcium (mg/1000 kcal) & -0.037 & $(-0.120$ to 0.043$)$ & 0.357 & 0.009 & $(-0.072$ to 0.089$)$ & 0.836 \\
\hline Iron (mg/1000 kcal) & -0.075 & $(-0.154$ to 0.003$)$ & 0.061 & -0.015 & $(-0.096$ to 0.066$)$ & 0.714 \\
\hline Vitamin D ( $\mu \mathrm{g} / 1000 \mathrm{kcal})$ & 0.028 & $(-0.049$ to 0.104$)$ & 0.486 & 0.045 & $(-0.035$ to 0.126$)$ & 0.270 \\
\hline Vitamin K ( $\mu \mathrm{g} / 1000$ kcal) & -0.085 & $(-0.162$ to -0.007$)$ & 0.033 & -0.009 & $(-0.089$ to 0.072$)$ & 0.834 \\
\hline Vitamin B-1 (mg/1000 kcal) & -0.036 & $(-0.120$ to 0.045$)$ & 0.370 & -0.047 & $(-0.126$ to 0.032$)$ & 0.240 \\
\hline Vitamin B-2 (mg/1000 kcal) & -0.041 & $(-0.122$ to 0.038$)$ & 0.299 & -0.004 & $(-0.083$ to 0.075$)$ & 0.918 \\
\hline Folic acid ( $\mu \mathrm{g} / 1000 \mathrm{kcal})$ & -0.078 & $(-0.164$ to 0.001$)$ & 0.053 & -0.026 & $(-0.107$ to 0.054$)$ & 0.515 \\
\hline Vitamin C (mg/1000 kcal) & -0.044 & $(-0.131$ to 0.037$)$ & 0.272 & -0.019 & $(-0.099$ to 0.060$)$ & 0.633 \\
\hline Cholesterol (mg/1000 kcal) & 0.010 & $(-0.070$ to 0.091$)$ & 0.805 & 0.034 & $(-0.045$ to 0.113$)$ & 0.399 \\
\hline Total dietary fiber (g/1000 kcal) & -0.052 & $(-0.132$ to 0.026$)$ & 0.186 & -0.004 & (- 0.083 to 0.074$)$ & 0.916 \\
\hline
\end{tabular}


Table 7 The relationship between mobile phone using and nutrient intake

\begin{tabular}{|c|c|c|c|c|c|c|}
\hline & Boys $(N=$ & & & Girls $(N=$ & & \\
\hline & $\bar{\beta}$ & Lower $\mathrm{Cl}$ to upper $\mathrm{Cl}$ & $p^{\dagger}$ & $\bar{\beta}$ & Lower $\mathrm{Cl}$ to upper $\mathrm{Cl}$ & $p^{\dagger}$ \\
\hline Protein (\%E) & -0.023 & $(-0.102$ to 0.057$)$ & 0.575 & 0.001 & $(-0.081$ to 0.084$)$ & 0.976 \\
\hline Fat (\%E) & 0.027 & $(-0.052$ to 0.108$)$ & 0.496 & 0.048 & $(-0.035$ to 0.133$)$ & 0.254 \\
\hline Carbohydrate (\%E) & -0.014 & $(-0.094$ to 0.067$)$ & 0.738 & -0.037 & $(-0.121$ to 0.046$)$ & 0.378 \\
\hline Saturated fatty acids (\%E) & 0.060 & $(-0.019$ to 0.139$)$ & 0.138 & 0.046 & $(-0.037$ to 0.129$)$ & 0.277 \\
\hline n-3 fatty acids (\%E) & -0.043 & $(-0.123$ to 0.036$)$ & 0.284 & 0.039 & $(-0.044$ to 0.122$)$ & 0.355 \\
\hline n-6 fatty acids (\%E) & -0.019 & ( -0.093 to 0.056$)$ & 0.626 & 0.021 & $(-0.061$ to 0.105$)$ & 0.610 \\
\hline Sodium (mg/1000 kcal) & -0.012 & ( -0.081 to 0.058$)$ & 0.751 & 0.012 & $(-0.061$ to 0.083$)$ & 0.767 \\
\hline Potassium (mg/1000 kcal) & -0.047 & $(-0.132$ to 0.033$)$ & 0.242 & -0.020 & $(-0.101$ to 0.062$)$ & 0.636 \\
\hline Calcium (mg/1000 kcal) & 0.009 & $(-0.072$ to 0.091$)$ & 0.823 & 0.013 & $(-0.069$ to 0.096$)$ & 0.754 \\
\hline Iron (mg/1000 kcal) & -0.036 & ( -0.115 to 0.043$)$ & 0.370 & 0.009 & $(-0.074$ to 0.091$)$ & 0.832 \\
\hline Vitamin D ( $\mu \mathrm{g} / 1000 \mathrm{kcal})$ & -0.013 & ( -0.089 to 0.063$)$ & 0.736 & 0.088 & (0.006 to 0.171$)$ & 0.036 \\
\hline Vitamin K ( $\mu \mathrm{g} / 1000$ kcal) & -0.089 & $(-0.166$ to -0.011$)$ & 0.026 & 0.026 & $(-0.056$ to 0.107$)$ & 0.536 \\
\hline Vitamin B-1 (mg/1000 kcal) & -0.020 & $(-0.103$ to 0.062$)$ & 0.624 & -0.014 & $(-0.095$ to 0.067$)$ & 0.737 \\
\hline Vitamin B-2 (mg/1000 kcal) & -0.011 & ( -0.091 to 0.068$)$ & 0.781 & -0.015 & (-0.095 to 0.066$)$ & 0.722 \\
\hline Folic acid ( $\mu \mathrm{g} / 1000 \mathrm{kcal})$ & -0.050 & $(-0.135$ to 0.030$)$ & 0.215 & -0.035 & $(-0.117$ to 0.047$)$ & 0.398 \\
\hline Vitamin C (mg/1000 kcal) & -0.019 & $(-0.103$ to 0.064$)$ & 0.643 & -0.012 & $(-0.093$ to 0.070$)$ & 0.779 \\
\hline Cholesterol (mg/1000 kcal) & 0.031 & $(-0.049$ to 0.111$)$ & 0.443 & 0.037 & $(-0.043$ to 0.119$)$ & 0.360 \\
\hline Total dietary fiber (g/1000 kcal) & -0.040 & $(-0.119$ to 0.038$)$ & 0.314 & -0.002 & (- 0.083 to 0.078$)$ & 0.954 \\
\hline
\end{tabular}

${ }^{\dagger}$ Multivariate linear regression analyses, adjusting for age, BMI, and physical activity

A relationship was observed between MP use and a lower intake of vitamin $\mathrm{K}(\beta=-0.089, p=0.026)$ in boys, and MP use and a higher intake of vitamin $\mathrm{D}(\beta=0.088$, $p=0.036)$ in girls.

\section{Discussion}

While many studies have investigated relationships among sedentary behaviors and diet, few have examined those among sedentary behaviors and nutrient intake in children and adolescents. Each of these health behaviors is an independent risk factor for chronic diseases, and thus, studies are required in order to establish whether these behaviors need to be targeted independently or jointly. Since technology-based sedentary behaviors may change quickly, relationships with new types of sedentary behaviors need to be examined. Therefore, the purpose of the present study was to elucidate the relationship between screen time and nutrient intake in children and adolescents. The results obtained showed a relationship between longer TV viewing times and less protein, minerals, vitamins, and total dietary fiber intake. Relationship between PC use in boys and less minerals and vitamins was also shown. On the contrary, PC use in girls and MP use was not strongly implicated in these nutrient intakes. Our results suggest that some types of screen time and nutrient intake do not occur in isolation.
A previous study that analyzed the combined data of boys and girls noted a negative relationship between TV viewing and protein intake [18], whereas this relationship was not detected in three other studies $[16,17]$. In the present study, we found negative relationships in boys and girls. TV viewing was negatively associated with calcium intake in three out of five previous studies $[15,17,18]$. We found that TV viewing negatively correlated with calcium intake in boys and girls. Although a previous study reported no correlation between TV viewing and iron intake [19], we found this relationship in boys. Previous studies reported a negative relationship between TV viewing and total dietary fiber [15, 17, 19-21]. This finding is consistent with the present results obtained from boys [22-24]. In addition to these results, negative correlations were observed between TV viewing and potassium, vitamin $\mathrm{K}$, and vitamin B-2 in boys, and sodium, vitamin $\mathrm{D}$, and vitamin B-2 in girls. Positive correlation was also found between TV viewing and $n-3$ fatty acids in girls.

A meta-analysis revealed that the relationship between weight status and screen time in young individuals was weak or inconsistent [25]. Weak or inconsistent relationship between screen time and weight status may be attributed to the moderating effects of nutrient intake. In other words, weight status may be related to nutritional consumption from screen time, resulting in inconsistencies in findings when investigating screen time and weight status only. A high frequency of the consumption 
of food in front of the TV has the potential to have an impact on the energy balance and, ultimately, body weight [15]. Sugar-sweetened beverages have been implicated in weight gain [26] and may be one of the mechanisms linking screen time with obesity.

Several mechanisms have been proposed to explain the relationship between screen behavior and dietary intake. One possible explanation is that children and adolescents with more screen time may be less physically active. This reduced PA may lead to a less healthy nutrient intake. However, we found a relationship between TV viewing and nutrient intake even after adjustments for PA. Another explanation is that screen users are exposed to numerous advertisements that may influence the type of food consumed [27]. A previous study on advertising and programming content reported the presence of frequent advertisements for "fast food, sugar-sweetened beverages, and other nutrient-poor calorically dense snacks along with a lack of content for low-calorie, nutrient-dense foods such as fruit and vegetables" [28]. Observed negative correlation between TV viewing and sodium intake may be due to more intake of such nutrient-poor foods instead of staple foods, main dishes, or side dishes which contain high levels of sodium in Japan. Furthermore, it has been hypothesized that individuals eat more while watching TV because they are distracted [29]. "Distracted eating" is "the dominance of the automatic system (over the reflective one) when making decisions pertaining to eating during TV viewing; that is, people are more likely to make emotional and uncontrolled decisions about eating and are less exposed to cues that would limit food intake when distracted by screen time" [29]. Experimental studies [30, 31] have shown that watching TV while eating may cause a distraction. Future studies are needed in order to elucidate the underlying mechanisms.

Due to the recent decrease in TV screen time and increase in PC and MP screen times among young individuals, the relationship between $\mathrm{PC}$ and $\mathrm{MP}$ use and nutrient intake differed from that between TV viewing and nutrition intake after adjustments for age, BMI, and PA. In girls, a positive correlation was observed between MP use and vitamin D intake, unexpectedly. MP use may have some good influence on nutrient intake in girls. However, we found such correlation only in vitamin D. We need more detailed analysis to unravel this finding. The relationship between $\mathrm{PC}$ use in girls and MP use and nutrient intake (Tables 2, 3, and 4) may be attributed to PA. PC use in girls and MP use may not have a similar effect as TV viewing.

From the perspective of public health, our results demonstrate that children and adolescents need to reduce the amount of time they spend watching TV as well as the frequency of eating in front of the TV screen in order to reduce health risks. Besides, girls need to be careful not to increase the amount of sodium they take. Boys need to reduce the time spent for using PC.

The strength of the present study is that we conducted a complete survey on children aged between 6 and 15 years old in one town. We also collected questionnaires at a high response rate. These strengths allowed us to examine the relationship between screen time and nutrient intake, excluding selection biases, especially non-respondent bias or volunteer bias, as much as possible.

The limitations of the present study were as follows. This study relied on self-reported screen times, which are only proxies of sedentary times and are subject to recall bias, even though self-report methods of quantifying screen time have been shown to have acceptable reliability and validity in children [32]. Furthermore, despite the use of a validated and detailed one-month food record, we cannot exclude possible measurement errors in nutrition. Therefore, adjustments for energy intake are suggested in order to reduce bias when examining the relationship between individuals' dietary intakes and other health-related outcomes. We adhered to this in the present study. Moreover, the BDHQ 10y and 15y do not include the calculation for supplements, which could influence calculation results of nutrient values. Another limitation is that the study design was cross-sectional in nature; therefore, the causality and directionality of relationships cannot be assessed. Future studies need to be longitudinal in design. In addition, we did not consider the similarities between participants from the same family.

\section{Conclusions}

The present results revealed that children and adolescents with longer TV viewing times have less protein, minerals, vitamins, and total dietary fiber. It was also revealed that boys with PC use have less minerals and vitamins. These results support the need to design intervention programs that focus on decreasing TV viewing times in both sexes and PC use in boys while encouraging adherence to dietary guidelines among children and adolescents. This is crucial because lifestyle habits are formed at an early age and are likely to track into adulthood.

\section{Abbreviations}

BDHQ: Brief self-administered dietary history questionnaire; BMI: Body mass index; Cl: Confidence interval; MP: Mobile phone; PA: Physical activity;

PC: Personal computer; SD: Standard deviation; SPSS: Statistical Package for Social Science; TV: Television

\section{Acknowledgements}

The Shika study was commissioned by Shika town. We would like to thank the study participants who responded to the survey and all of our colleagues at the Department of Environmental and Preventive Medicine, Graduate School of Medical Sciences, Kanazawa University. 


\section{Funding}

This study was supported by a Grant-in-Aid for Scientific Research (C) by the Ministry of Education, Culture, Sport, Science and Technology (MEXT), number $15 \mathrm{~K} 08729$.

\section{Availability of data and materials}

The datasets used and analyzed during this study are not publicly available due to possibility of compromise of individual privacy, but are available from the corresponding author on reasonable request.

\section{Authors' contributions}

HN designed the study; HT acquired the data. HT analyzed the data. HN advised on statistical issues. All authors discussed data analyses and interpreted the results. HT wrote the first draft of the manuscript. All authors critically revised and approved the final manuscript. All authors agreed to be accountable for all aspects of the work in ensuring that questions related to the accuracy or integrity of any part of the work are appropriately investigated and resolved.

\section{Ethics approval and consent to participate}

The Shika study protocols were approved by the Kanazawa University Ethical Committee (No.1464). Written informed consent was obtained from the guardians of all participants prior to data collection.

\section{Consent for publication}

Not applicable

\section{Competing interests}

The authors declare that they have no competing interests.

\section{Publisher's Note}

Springer Nature remains neutral with regard to jurisdictional claims in published maps and institutional affiliations.

\section{Author details}

'Department of Environmental and Preventive Medicine, Graduate School of Medical Sciences, Kanazawa University, 13-1 Takaramachi, Kanazawa, Ishikawa, Japan. ${ }^{2}$ Third Department of Internal Medicine, University of Fukui Faculty of Medical Sciences, 23-3 Matsuokashimoaiduki, Eiheiji, Fukui, Japan. 3 Department of Social and Preventive Epidemiology, School of Public Health, The University of Tokyo, 7-3-1 Hongo, Bunkyoku, Tokyo, Japan.

\section{Received: 20 March 2018 Accepted: 17 July 2018}

\section{Published online: 07 August 2018}

\section{References}

1. Sedentary Behavior Research Network. Letter to the Editor: standardized use of the terms "sedentary" and "sedentary behaviours.". Appl Physiol Nutr Metab. 2012:37:540-2. https://doi.org/10.1139/h2012-024.

2. Leech RM, Mcnaughton SA, Timperio A. The clustering of diet, physical activity and sedentary behavior in children and adolescents: a review. Int J Behav Nutr Phys Act. 2014; https://doi.org/10.1186/1479-5868-11-4.

3. Dietz H, Gortmaker L. Do we fatten our children at the television set? Obesity and television viewing in chldren and adolescents. Pediatrics. 1985; 75:807-12

4. Pearson N, Biddle SJH. Sedentary behavior and dietary intake in children, adolescents, and adults: a systematic review. Am J Prev Med. 2011;41:17888. https://doi.org/10.1016/j.amepre.2011.05.002.

5. Pearson N, Biddle SJH, Hobbs M, Pearson N, Foster PJ, Biddle SJH. Sedentary behaviour and diet across the lifespan: an update systematic review. $\mathrm{Br} J$ Sports Med. 2014;49:1179-88. https://doi.org/10.1136/bjsports-2014-093754.

6. WHO: Obesity and overweight . http://www.who.int/mediacentre/ factsheets/fs311/en/. Accessed 1 Mar 2018.

7. Fletcher E, Leech R, Mcnaughton SA, Dunstan DW, Lacy KE, Salmon J. Is the relationship between sedentary behaviour and cardiometabolic health in adolescents independent of dietary intake? A systematic review. Obes Rev. 2015:16:795-805. https://doi.org/10.1111/obr.12302

8. Tremblay MS, Leblanc AG, Janssen I, Kho ME, Hicks A, Murumets K, et al. Canadian sedentary behaviour guidelines for children and youth. Appl Physiol Nutr Metab. 2011;36:59-64; 65-71. https://doi.org/10.1139/H11-012.
9. Sasaki S, Yanagibori R, Amano K. Self-administered diet history questionnaire developed for health education: a relative validation of the test-version by comparison with 3-day diet record in women. J Epidemiol. 1998;8:203-15.

10. Asakura K, Haga M, Sasaki S. Relative validity and reproducibility of a brief-type self-administered diet history questionnaire for Japanese children aged 3-6 years: application of a questionnaire established for adults in preschool children. J Epidemiol. 2015;25:341-50. https://doi.org/10.2188/jea.JE20140174

11. Okuda M, Sasaki S, Bando N, Hashimoto M, Kunitsugu I, Sugiyama S, et al. Carotenoid, tocopherol, and fatty acid biomarkers and dietary intake estimated by using a brief self-administered diet history questionnaire for older Japanese children and adolescents. J Nutr Sci Vitaminol. 2009;55:231-41.

12. Okubo H, Sasaki S, Rafamantanantsoa HH, Ishikawa-Takata K, Okazaki H, Tabata I. Validation of self-reported energy intake by a self-administered diet history questionnaire using the doubly labeled water method in 140 Japanese adults. Eur J Clin Nutr. 2008:62:1343-50.

13. Kobayashi S, Honda S, Murakami K, Sasaki S, Okubo H, Hirota N, et al. Both comprehensive and brief self-administered diet history questionnaires satisfactorily rank nutrient intakes in Japanese adults. J Epidemiol. 2012;22:151-9.

14. Kobayashi S, Murakami K, Sasaki S, Okubo H, Hirota N, Notsu A, et al. Comparison of relative validity of food group intakes estimated by comprehensive and brief-type self-administered diet history questionnaires against 16 d dietary records in Japanese adults. Public Health Nutr. 2011;14: 1200-11. https://doi.org/10.1017/S1368980011000504.

15. Halford JCG, Boyland EJ, Hughes G, Oliveira LP, Dovey TM. Beyond-brand effect of television (TV) food advertisements/commercials on caloric intake and food choice of 5-7-year-old children. Appetite. 2007:49:263-7.

16. Cole TJ. Establishing a standard definition for child overweight and obesity worldwide: international survey. BMJ. 2000;320:1240-3. https://doi.org/10. 1136/bmj.320.7244.1240

17. Ottevaere C, Huybrechts I, Benser J, De Bourdeaudhuij I, Cuenca-garcia M, Dallongeville J, et al. Clustering patterns of physical activity, sedentary and dietary behavior among European adolescents: the HELENA study. 2011;11: 328. https://doi.org/10.1186/1471-2458-11-328.

18. Miller SA, Taveras EM, Rifas-Shiman SL, Gillman MW. Association between television viewing and poor diet quality in young children. Int J Pediatr Obes. 2008:3:168-76. https://doi.org/10.1080/17477160801915935.

19. Ortega RM, Andrés P, Requejo AM, López-Sobaler AM, Redondo MR González-Fernández M. Influence of the time spent watching television on the dietary habits, energy intake and nutrient intake of a group of Spanish adolescents. Nutr Res. 1996;16:1467-70.

20. Kourlaba G, Kondaki K, Liarigkovinos T, Manios Y. Factors associated with television viewing time in toddlers and preschoolers in Greece: the GENESIS study. J Public Health (Oxf). 2009;31:222-30. https://doi.org/10.1093/pubmed/fdp011.

21. Vereecken CA, Todd J, Roberts C, Mulvihill C, Maes L. Television viewing behaviour and associations with food habits in different countries. Public Health Nutr. 2006:9:244-50

22. Ford C, Ward D, White M. Television viewing associated with adverse dietary outcomes in children ages 2-6. Obes Rev. 2012;13:1139-47. https://doi.org/ 10.1111/j.1467-789X.2012.01028.X.

23. Ayala GX, Baquero B, Arredondo EM, Campbell N, Larios S, Elder JP. Association between family variables and Mexican American children's dietary behaviors. J Nutr Educ Behav. 2007;39:62-9.

24. Bowman SA. Television-viewing characteristics of adults: correlations to eating practices and overweight and health status. Prev Chronic Dis. 2006;3:A38.

25. Marshall SJ, Biddle SJH, Gorely T, Cameron N, Murdey I. Relationships between media use, body fatness and physical activity in children and youth: a meta-analysis. Int J Obes Relat Metab Disord. 2004;28:1238-46.

26. Malik VS, Schulze MB, Hu FB. Intake of sugar-sweetened beverages and weight gain: a systematic review. Am J Clin Nutr. 2006;84:274-88.

27. Dennison BA, Edmunds LS. The role of television in childhood obesity. Prog Pediatr Cardiol. 2008;25:191-7.

28. Story M, Faulkner P. The prime time diet: a content analysis of eating behavior and food messages in television program content and commercials. Am J Public Health. 1990:80:738-40.

29. Marsh S, Ni Mhurchu C, Maddison R. The non-advertising effects of screenbased sedentary activities on acute eating behaviours in children, adolescents, and young adults. A systematic review. Appetite. 2013;71:25973. https://doi.org/10.1016/j.appet.2013.08.017.

30. Bellissimo N, Pencharz PB, Thomas SG, Anderson GH, Sciences N, Medicine F. Effect of television viewing at mealtime on food intake after a glucose preload in boys. Pediatr Res. 2007;61:754-9. 
31. Blass EM, Anderson DR, Kirkorian HL, Pempek TA, Price I, Koleini MF. On the road to obesity: television viewing increases intake of high-density foods. Physiol Behav. 2006;88:597-604.

32. Hardy LL. Diagnostic in obesity and its comorbidities a systematic review of the validity and reliability of sedentary behaviour measures used with children. Obes Rev. 2011:781-99. https://doi.org/10.1111/j. 1467-789X.2011.00896.X.

Ready to submit your research? Choose BMC and benefit from:

- fast, convenient online submission

- thorough peer review by experienced researchers in your field

- rapid publication on acceptance

- support for research data, including large and complex data types

- gold Open Access which fosters wider collaboration and increased citations

- maximum visibility for your research: over $100 \mathrm{M}$ website views per year

At $\mathrm{BMC}$, research is always in progress.

Learn more biomedcentral.com/submissions 